\title{
The prevalence and determinants of poor glycemic control among adults with type 2 diabetes mellitus in Saudi Arabia
}

This article was published in the following Dove Press journal:

Diabetes, Metabolic Syndrome and Obesity:Targets and Therapy

\author{
Riyadh A Alzaheb' \\ Abdullah H Altemani \\ 'Department of Clinical Nutrition, \\ Faculty of Applied Medical Sciences, \\ 2Department of Family and \\ Community Medicine, Faculty of \\ Medicine, University of Tabuk, Tabuk, \\ Saudi Arabia
}

Background: Although the prevalence of type 2 diabetes mellitus (T2DM) is rising sharply in Saudi Arabia, data on glycemic control, crucial to reducing diabetes mellitus complications, remain scarce. This study therefore investigated glycemic control status and the factors influencing poor glycemic control among adult T2DM patients in Saudi Arabia.

Methods: This cross-sectional study examined 423 T2DM patients at a diabetic center in Tabuk, Saudi Arabia between September 2016 and July 2017. Glycemic levels were measured via fasting blood glucose (FBG) levels, and "poor glycemic control" was defined as FBG >130 mg/dL. Poor glycemic control's risk factors were identified using a logistic regression.

Results: In the sample, $74.9 \%$ of the patients had poor blood glycemic control. Logistic regression revealed that T2DM patients had an increased chance of poorly controlled diabetes if they had family histories of diabetes (adjusted odds ratio [AOR] $=7.38,95 \% \mathrm{CI} 4.09-13.31$ ), longer diabetic durations $(\mathrm{AOR}=2.33,95 \% \mathrm{CI} 1.14-4.78$ for $5-10$ years and $\mathrm{AOR}=5.19,95 \% \mathrm{CI}$ 2.50-10.69 for $>10$ years), insufficient physical exercise (AOR $=19.02,95 \%$ CI 6.23-58.06), or were overweight ( $\mathrm{AOR}=3.79,95 \% \mathrm{CI} 2.00-7.18)$, or obese $(\mathrm{AOR}=5.35,95 \% \mathrm{CI} 2.72-12.59)$. Conclusion: A high proportion of the sampled patients had poor glycemic control, therefore, health care professionals should manage the associated risk factors to limit disease complications and improve the health of patients with diabetes.

Keywords: type 2 diabetes, glycemic control, Saudi Arabia

\section{Introduction}

Diabetes mellitus refers to a grouping of metabolic diseases involving prolonged hyperglycemia caused by the inadequate secretion of insulin, poor insulin action, or a combination of the two. ${ }^{1}$ Diabetes is a globally chronic disease affecting 366 million people, a number which has been forecast to rise to 552 million by $2030 .^{2}$ It has various long-term complications which negatively impact the individuals' quality of life and potentially their lifespans, causing deleterious effects for both individuals and societies. ${ }^{3}$ Diabetes complications are categorized as microvascular (nephropathy, neuropathy, retinopathy) or macrovascular (cardiovascular and cerebrovascular disease). ${ }^{4}$ Diabetes management aims to delay the onset of disease complications, and to hinder its progression, mostly by improving glycemic control and controlling the risk of cardiovascular disease..$^{5,6}$

Previous studies have provided evidence of the power of good glycemic control to restrict the microvascular and macrovascular complications of diabetes. ${ }^{6-8}$ Despite that, between $40 \%$ and $60 \%$ of patients worldwide still have poorly controlled diabetes. ${ }^{9-13}$
Correspondence: Riyadh A Alzaheb Department of Clinical Nutrition, Faculty of Applied Medical Sciences, University of Tabuk, Tabuk 7I49I, Saudi Arabia

Tel/Fax+966 I44 562723

Email ralzaheb@ut.edu.sa 
High glycemic control is difficult to achieve, and prior research has reported many factors as contributing to poor control among patients, including their age, gender, level of education, weight, smoking status, marital status, the duration of diabetes, the medications taken, and numerous other factors. ${ }^{14-16}$ However, it has been proved difficult to confirm exactly which of these factors are most directly associated with poor glycemic control. ${ }^{15}$ This is because the prior findings are inconsistent, and have also indicated that glycemic control and the factors influencing it vary across countries and between different ethnic groups. ${ }^{17,18}$ There is, therefore, an obvious need for better understanding of the factors affecting glycemic control so that diabetes management can be improved. ${ }^{19}$

The International Diabetes Federation has confirmed that Saudi Arabia is among the global top 10 countries with the highest diabetes rates among adults aged between 20 and 79 years. ${ }^{20}$ Further, the prevalence in Saudi Arabia has risen sharply in recent decades, from $7 \%$ in 1989 to $32 \%$ in $2009 .{ }^{21}$ Despite this alarming trend, the factors linked to glycemic control among type 2 diabetes mellitus (T2DM) patients remain poorly understood. ${ }^{22}$ This study therefore recruited a sample of adult T2DM patients in Saudi Arabia to evaluate their glycemic control status and its determinants.

\section{Methods}

\section{Study design and participants}

This cross-sectional observational study recruited a sample of adult outpatients attending a diabetes clinic at a diabetic center in Tabuk, the capital city of the Tabuk region of Saudi Arabia, between September 2016 and July 2017. Patients who have been diagnosed with diabetes are given referrals to this center by local hospitals and primary health care centers (PHCCs).

The size of the required sample was established according to the following assumptions: $\pi=0.5$ (there has been no prior estimate of the prevalence of poor glycemic control among type 2 diabetics in the Tabuk region); desired marginal error $=0.05$; and $z($ or $95 \%$ confidence level $)=1.96$. The ideal total sample size was therefore calculated as 385 patients. After allowing an additional $20 \%$ to account for nonrespondents, the final sample size was set at $\sim 460$ patients.

To be eligible to participate in the study, patients had to be at least 18 years old, to have received a confirmed diagnosis of T2DM, and to have received treatment as outpatients for a minimum of 1 year. Pregnant patients, patients suffering from diagnosed mental illness or psychological issues, and patients diagnosed with renal failure were excluded. All eligible patients were invited to participate in the study, and those who agreed were given a written informed consent form to sign. Ethical approval for the research was sought and obtained from the Committee of Research Ethics at the University of Tabuk in 2016.

\section{Data collection}

Data were collected during direct encounters between trained investigators and participating patients via a fourpart questionnaire specially designed for the research, to ensure a high level of information accuracy. The first part of the questionnaire involved sociodemographic data on the participating patients' age, marital status, gender, residence, education level, employment status, and income. The second part concerned their clinical characteristics, including family histories of diabetes, the duration of disease, and self-reported comorbidities. The third part gathered lifestyle data on the patients' smoking status, whether they exercised regularly (ie, whether they were involved in at least 30 minutes of exercise per day, at least 3 days per week), and whether they followed a set dietary plan approved by dietitians (which restricted their intakes of sugar, salt, and fat). The fourth and final part had questions on the medications the patients were taking to manage their diabetes, and whether they self-monitored their blood glucose levels.

A pilot study was performed using 20 patients with T2DM to test the questionnaire and inform any necessary changes based on an assessment of their feedback. The pilot study established that the questionnaire required about 15 minutes to complete, and patients who participated in this study were removed from the final study sample.

The height and weight of each patient were measured while they wore lightweight clothing and no shoes. Their weight was measured to the nearest $0.5 \mathrm{~kg}$ and their height to the nearest $0.5 \mathrm{~cm}$ so that their body mass index (BMI) could be calculated using the formula of weight in kilograms divided by height in meters squared. Based on the calculated BMI, the patients were divided into categories reflecting the World Health Organization (WHO)'s definitions: normal range $\left(\mathrm{BMI}=18.5-24.9 \mathrm{~kg} / \mathrm{m}^{2}\right)$, overweight $(\mathrm{BMI}=25-29.9$ $\mathrm{kg} / \mathrm{m}^{2}$ ), and obese (BMI $\left.\geq 30 \mathrm{~kg} / \mathrm{m}^{2}\right){ }^{23}$

Data on the patients' fasting blood glucose (FBG) levels were taken either from their personal medical records, if it had been tested within 3 months prior to the research encounter and provided the patients were still taking the same medication when the encounter took place as they had been on at the time of the FBG test, or alternatively, they were tested during the period of study. Each patient's glycemic level was coded 
as either poor or good. Poor glycemic control was defined in this study as an FBG level above $130 \mathrm{mg} / \mathrm{dL}{ }^{24}$

\section{Statistical analyses}

The data were analyzed using the SPSS program, version 23 (IBM Corporation, Armonk, NY, USA). Statistical significance was set at a $p$-value of $<0.05$. Data were expressed as counts (frequency, $\mathrm{n}$ ) and proportions (\%). A univariate logistic regression was performed to identify the factors associated with poor glycemic control in the study sample. Then, the variables highlighted as significant by the univariate logistic regression were included in a multivariate logistic regression, to identify associations between possible risk factors and poor diabetes control. The analysis also calculated the odds ratios and their $95 \%$ confidence intervals (CIs).

\section{Results}

A total of 460 T2DM patients were sent invitations to participate in the study, of whom $423(92 \%)$ returned completed questionnaires.

The characteristics of the patients with T2DM are presented in Table 1, which shows that $233(52.7 \%)$ were male; $278(65.7 \%)$ were aged 30-49 years; $384(90.8 \%)$ were married; 309 (73.0\%) lived in an urban area; 395 (93.4\%) had completed at least primary or higher education; 189 (44.7\%) earned a middle-level income; and 278 (65.7\%) were employed. Importantly, it also shows that almost three quarters of the patients (72.3\%) were either overweight or obese.

The prevalence of poor glycemic control in this study sample of T2DM patients was $74.9 \%$. The univariate logistic regression analysis results shown in Table 2 indicate a substantially greater risk of poor glycemic control among patients living in urban areas, with a family history of diabetes mellitus, who reported longer diabetic durations, who had insufficient physical exercise, who did not adhere to a diabetic dietary plan approved by a dietician, who failed to perform regular self-monitoring of their blood glucose, and who were overweight or obese.

An adjusted multivariate logistic analysis was carried out to establish the independent predictors of glycemic control for the study sample. In the present research, variables with a $p$-value of $<0.05$ in the univariate analysis were used in the multivariate analysis (Table 3 ). The results of the multivariate logistic analysis revealed that T2DM patients were more likely to have poorly controlled diabetes if they had a family history of diabetes mellitus (adjusted odds ratio $[\mathrm{AOR}]=7.38$, 95\% CI 4.09-13.31), had longer diabetic durations (AOR $=2.33,95 \%$ CI $1.14-4.78$ for $5-10$ years and $\mathrm{AOR}=5.19$,
Table I Sociodemographic characteristics of the study participants $(n=423)$

\begin{tabular}{|c|c|c|}
\hline Variables & $\mathbf{N}$ & $\%$ \\
\hline \multicolumn{3}{|l|}{ Gender } \\
\hline Male & 223 & 52.7 \\
\hline Female & 200 & 47.3 \\
\hline \multicolumn{3}{|l|}{ Age group (years) } \\
\hline$<29$ & 62 & 14.7 \\
\hline $30-39$ & 101 & 23.9 \\
\hline $40-49$ & 177 & 41.8 \\
\hline$>50$ & 83 & 19.6 \\
\hline \multicolumn{3}{|l|}{ Marital status } \\
\hline Married & 384 & 90.8 \\
\hline Unmarried & 39 & 9.2 \\
\hline \multicolumn{3}{|l|}{ Type of residence } \\
\hline Rural & 114 & 27.0 \\
\hline Urban & 309 & 73.0 \\
\hline \multicolumn{3}{|l|}{ Education level } \\
\hline Tertiary & 159 & 37.6 \\
\hline Secondary (grade 7-12) & 161 & 38.1 \\
\hline Primary (grade I-6) & 75 & 17.7 \\
\hline Illiterate & 28 & 6.6 \\
\hline \multicolumn{3}{|l|}{ Income status } \\
\hline Low $(<5000$ SAR $)$ & 127 & 30.0 \\
\hline Middle (5000-15,000 SAR) & 189 & 44.7 \\
\hline High (>15,000 SAR) & 107 & 25.3 \\
\hline \multicolumn{3}{|l|}{ Employment status } \\
\hline Employed & 278 & 65.7 \\
\hline Unemployed & 145 & 34.3 \\
\hline \multicolumn{3}{|l|}{ BMI $\left(\mathrm{kg} / \mathrm{m}^{2}\right)$} \\
\hline Normal $(<25)$ & 117 & 27.7 \\
\hline Overweight (25-29.9) & 215 & 50.8 \\
\hline Obese $(\geq 30)$ & 91 & 21.5 \\
\hline
\end{tabular}

Abbreviations: BMI, body mass index; SAR, Saudi Arabian Riyal ( $\approx \$ 0.266)$.

95\% CI 2.50-10.69 for $>10$ years), did not undertake sufficient physical exercise ( $\mathrm{AOR}=19.02,95 \%$ CI 6.23-58.06), and $/$ or were overweight ( $\mathrm{AOR}=3.79,95 \% \mathrm{CI} 2.00-7.18$ ) or obese $(\mathrm{AOR}=5.35,95 \%$ CI 2.72-12.59).

\section{Discussion}

The results of the analyses indicated that $74.9 \%$ of the study sample of patients with T2DM suffered from poor glycemic control. The high prevalence of uncontrolled T2DM reported in this research is of concern, and is also broadly in line with prior studies in other regions of Saudi Arabia. A previous study reported that $67.7 \%$ of T2DM patients had poor glycemic control in Riyadh (the capital of Saudi Arabia). ${ }^{25}$ A similar value, $67.9 \%$, was found in $\mathrm{Al}$ Hasa (the eastern province), and $74 \%$ in Jazan (the southwestern province)..$^{22,26}$ High prevalence of poor diabetes control has also been identified in other Middle Eastern contexts; for example, $65.0 \%$ in Oman, $65.1 \%$ in Jordan, 69\% in the United Arab Emirates, 
Table 2 Results of the univariate logistic regression analysis of factors associated with poor glycemic control $(n=423)$

\begin{tabular}{|c|c|c|c|c|}
\hline \multirow[t]{2}{*}{ Variables } & \multicolumn{2}{|c|}{ Glycemic control status, n (\%) } & \multicolumn{2}{|c|}{ Unadjusted } \\
\hline & Poor $(n=317,74.9 \%)$ & Good $(n=106,25.1 \%)$ & OR & $95 \% \mathrm{Cl}$ \\
\hline \multicolumn{5}{|l|}{ Gender } \\
\hline Male & $164(73.5)$ & $59(26.5)$ & 1 & Ref \\
\hline Female & $153(76.5)$ & $47(23.5)$ & 1.17 & $0.75-1.82$ \\
\hline \multicolumn{5}{|l|}{ Age group (years) } \\
\hline$<29$ & $49(79.0)$ & I3 (2I.0) & I & Ref \\
\hline $30-39$ & $69(68.3)$ & $32(31.7)$ & 0.57 & $0.27-1.20$ \\
\hline $40-49$ & $136(76.8)$ & $4 I(23.2)$ & 0.88 & $0.44-1.78$ \\
\hline$>50$ & $63(75.9)$ & $20(24.1)$ & 0.84 & $0.38-1.85$ \\
\hline \multicolumn{5}{|l|}{ Marital status } \\
\hline Married & $287(74.7)$ & $97(25.3)$ & I & Ref \\
\hline Unmarried & 30 (76.9) & $9(23.1)$ & 1.13 & $0.52-2.46$ \\
\hline \multicolumn{5}{|l|}{ Type of residence } \\
\hline Rural & $73(64.0)$ & $4 I(36.0)$ & I & Ref \\
\hline Urban & $244(79.0)$ & $65(21.0)$ & 2.11 & $1.32-3.37$ \\
\hline \multicolumn{5}{|l|}{ Education level } \\
\hline Tertiary & $12 \mid(76.1)$ & $38(23.9)$ & I & Ref \\
\hline Secondary (grade 7-12) & II $4(70.8)$ & $47(29.2)$ & 1.44 & $0.5 I-4.06$ \\
\hline Primary (grade I-6) & $59(78.7)$ & $16(21.3)$ & 1.16 & $0.60-2.25$ \\
\hline Illiterate & $23(82.1)$ & $5(17.9)$ & 0.76 & $0.46-1.25$ \\
\hline \multicolumn{5}{|l|}{ Income status } \\
\hline Low $(<5000$ SAR $)$ & 90 (70.9) & $37(29.1)$ & 1 & Ref \\
\hline Middle (5000-I5,000 SAR) & $145(76.7)$ & $44(23.3)$ & 1.36 & $0.8 \mathrm{I}-2.26$ \\
\hline High $(>15,000$ SAR) & $82(76.6)$ & $25(23.4)$ & 1.35 & $0.75-2.43$ \\
\hline \multicolumn{5}{|l|}{ Employment status } \\
\hline Employed & $204(73.4)$ & $74(26.6)$ & I & Ref \\
\hline Unemployed & I I 3 (77.9) & $32(22 . I)$ & 1.28 & $0.80-2.06$ \\
\hline \multicolumn{5}{|l|}{ Family history of diabetes } \\
\hline No & $63(48.1)$ & $68(51.9)$ & 1 & Ref \\
\hline Yes & $254(87.0)$ & $38(13.0)$ & 7.22 & $4.45-11.70$ \\
\hline \multicolumn{5}{|l|}{ Diabetes duration (years) } \\
\hline$<5$ & $106(62.4)$ & $64(37.6)$ & I & Ref \\
\hline $5-10$ & $92(81.4)$ & $21(18.6)$ & 2.65 & $1.50-4.67$ \\
\hline$>10$ & $119(85.0)$ & $21(15.0)$ & 3.42 & $1.96-5.98$ \\
\hline \multicolumn{5}{|l|}{ Comorbidity } \\
\hline Diabetes mellitus only & III (70.7) & $46(29.3)$ & I & Ref \\
\hline Diabetes mellitus and comorbidity & $206(77.4)$ & $60(22.6)$ & 1.42 & $0.91-2.23$ \\
\hline \multicolumn{5}{|l|}{ Smoking status } \\
\hline Smoker & $62(75.6)$ & $20(24.4)$ & I & Ref \\
\hline Nonsmoker & $255(74.8)$ & $86(25.2)$ & 0.96 & $0.55-1.68$ \\
\hline \multicolumn{5}{|c|}{ Performs at least 30 min exercise 3 days per week } \\
\hline No & $221(87.0)$ & $33(13.0)$ & 5.09 & $3.16-8.20$ \\
\hline Yes & $96(56.8)$ & $73(43.2)$ & I & Ref \\
\hline \multicolumn{5}{|c|}{ On a dietary plan recommended by dietitians } \\
\hline No & $229(82.7)$ & $48(17.3)$ & 3.14 & $1.99-4.95$ \\
\hline Yes & $88(60.3)$ & $58(39.7)$ & I & Ref \\
\hline \multicolumn{5}{|l|}{ Diabetes treatment } \\
\hline Diet and exercise & $15(65.2)$ & $8(34.8)$ & I & Ref \\
\hline Oral antidiabetic agents only & $156(73.2)$ & $57(26.8)$ & 1.46 & $0.59-3.63$ \\
\hline Insulin only & $99(78.0)$ & $28(22.0)$ & 1.89 & $0.73-4.90$ \\
\hline Oral antidiabetic agents and insulin & $47(78.3)$ & $13(21.7)$ & 1.93 & $0.67-5.54$ \\
\hline Self-monitoring blood glucose & & & & \\
\hline No & $24 I(80.3)$ & $59(19.7)$ & 2.53 & $1.60-4.0 \mid$ \\
\hline Yes & $76(6 \mid .8)$ & $47(38.2)$ & I & Ref \\
\hline BMI $\left(\mathrm{kg} / \mathrm{m}^{2}\right)$ & & & & \\
\hline Normal $(<25)$ & $66(56.4)$ & $51(43.6)$ & I & Ref \\
\hline Overweight $(25$ to $<30)$ & I75 (8I.4) & $40(18.6)$ & 3.38 & $2.05-5.58$ \\
\hline Obese $(\geq 30)$ & $76(83.5)$ & $15(16.5)$ & 3.92 & $2.02-7.60$ \\
\hline
\end{tabular}

Abbreviations: BMI, body mass index; $\mathrm{Cl}$, confidence interval; OR, odds ratio; Ref, reference; SAR, Saudi Arabian Riyal ( $\$ 0.266)$. 
Table 3 Results of the multivariate logistic regression analysis of factors associated with poor glycemic control $(n=423)$

\begin{tabular}{|c|c|c|}
\hline \multirow[t]{2}{*}{ Variables } & \multicolumn{2}{|c|}{ Adjusted } \\
\hline & OR & $95 \% \mathrm{Cl}$ \\
\hline \multicolumn{3}{|l|}{ Type of residence } \\
\hline Rural & I & Ref \\
\hline Urban & 1.61 & $0.87-3.01$ \\
\hline \multicolumn{3}{|l|}{ Family history of diabetes } \\
\hline No & I & Ref \\
\hline Yes & 7.38 & $4.09-|3.3|$ \\
\hline \multicolumn{3}{|l|}{ Diabetes duration (years) } \\
\hline$<5$ & 1 & Ref \\
\hline $5-10$ & 2.33 & $1.14-4.78$ \\
\hline$>10$ & 5.19 & $2.50-10.69$ \\
\hline \multicolumn{3}{|c|}{ Performs at least 30 min exercise 3 days per week } \\
\hline No & 19.02 & $6.23-58.06$ \\
\hline Yes & I & Ref \\
\hline \multicolumn{3}{|c|}{ On a dietary plan recommended by dietitians } \\
\hline No & 0.54 & $0.31-2.19$ \\
\hline Yes & I & Ref \\
\hline \multicolumn{3}{|l|}{ Self-monitoring blood glucose } \\
\hline No & 0.69 & $0.23-2.09$ \\
\hline Yes & I & Ref \\
\hline \multicolumn{3}{|l|}{ BMI $\left(\mathrm{kg} / \mathrm{m}^{2}\right)$} \\
\hline Normal $(<25)$ & I & Ref \\
\hline Overweight $(25$ to $<30)$ & 3.79 & $2.00-7.18$ \\
\hline Obese $(\geq 30)$ & 5.35 & $2.72-12.59$ \\
\hline
\end{tabular}

Abbreviations: $\mathrm{BMI}$, body mass index; $\mathrm{Cl}$, confidence interval; OR, odds ratio; Ref, reference.

and $78.8 \%$ in Kuwait. ${ }^{27-30}$ The overall picture established by prior research is of a generally high prevalence of poor glycemic control, which is a matter of significant concern both in Saudi Arabia and more broadly across the Middle East because of the negative health implications for patients with poorly controlled T2DM.

Both modifiable and non-modifiable factors shape glycemic control's etiology and affect the extent of poor glycemic control in T2DM patients. ${ }^{31}$ Further, glycemic control and the factors influencing it vary across countries and between ethnicities, making it vital to determine the factors causing poor glycemic control among Saudi T2DM patients. ${ }^{17,18}$ This research has identified four variables which appear to be associated with glycemic control as an outcome: patients' family history, duration of diabetes, exercise levels, and weight status. Of these four factors, family history and diabetes duration are non-modifiable risk factors which raise the likelihood of poorly controlled diabetes; more specifically, a heightened risk emerges if a patient has a family history of diabetes, and/or has had the disease for a long time. The present findings are in line with those of prior studies. ${ }^{19,22,25,28,31-34}$ A feasible explanation of why patients with a history of T2DM are at greater risk of having poor glycemic control is that the disease has inherent genetic risk factors which have the power to influence its duration and severity. ${ }^{35} \mathrm{~A}$ longer T2DM duration is also associated with poor glycemic control, perhaps because of the progressive restriction of insulin secretion over time caused by B-cell failure which means that a patient's positive response to changes in diet, or oral agents, is less likely. ${ }^{6}$

The present investigation has also identified a significant association between low levels of physical activity and poor glycemic control, as poor glycemic control was observed to be less common among those undertaking regular physical exercise than in those taking part in infrequent activity. This result builds a consensus with prior research, which has also associated physical inactivity with high glucose levels. ${ }^{28,36-38}$ Further, physical exercise has not only been reported to raise glycemic control, but also to boost a patient's insulin sensitivity and to repair some of the damage caused by diabetesassociated complications, such as impaired cardiovascular health, one of the most common complications. ${ }^{39}$ Regrettably, a recent study of the barriers to successfully control T2DM in a Saudi Arabian context found low levels of physical activity to be extremely common. ${ }^{40}$ For instance, a cross-sectional study with a sample of 450 Saudi participants who were attending PHCCs in Riyadh, the capital city of Saudi Arabia, found that $82 \%$ of the participants were physically inactive. ${ }^{41}$ The obvious explanation for this remarkably high prevalence is that Saudi Arabia is a very hot country, so T2DM sufferers are discouraged from performing exercise outdoors. ${ }^{22}$ Because physical inactivity (caused by a sedentary lifestyle) is a modifiable risk factor for poor diabetes control, further research investigating the barriers to exercise, including, for example, access to gym facilities in Saudi Arabia, would be useful in establishing how to raise levels of daily physical activity across the Saudi population.

Overweight and obesity is another important modifiable factor influencing poor glycemic control and diabetes risk. ${ }^{42}$ Prior research has reported that the glycemic control of patients with T2DM generally deteriorates when they gain weight, and improves when they lose weight. ${ }^{28,43-47}$ Furthermore, rapid and substantial weight loss such as that which can occur, for example, in association with gastric bypass surgery, has been found to cause partial or total T2DM remission. ${ }^{48}$ The present research agrees with previous findings regarding the higher likelihood of poorly controlled T2DM among overweight or obese patients, possibly because these patients often have higher dietary intakes of food high in carbohydrates and a high glycemic index, thus enhancing their fat storage and making their glycemic 
levels harder to control. Excessive storage of fat and high glucose levels due to carbohydrate overconsumption make good glycemic control difficult. ${ }^{34}$ Unfortunately, WHO has reported that Gulf Arab countries, including Saudi Arabia, Kuwait, Bahrain, and the United Arab Emirates, are ranked among the top 10 countries globally for obesity. ${ }^{49}$ A prior study has also found that between $80 \%$ and $90 \%$ of Saudi T2DM patients are obese. ${ }^{40}$ Our results regarding the levels of overweight and obesity among diabetic patients are a little better, as approximately three quarters of the research patients with T2DM (72.3\%) were in this category. This research therefore emphasizes the need to design strategies encouraging T2DM patients to make long-term lifestyle changes involving specific diet and exercise recommendations which can facilitate weight loss and raise their levels of glycemic control.

The present research has some inherent limitations. Firstly, the cross-sectional design of the study meant that it could not establish a cause-and-effect association between poor glycemic control and its influencing factors. Secondly, the self-reported responses to some items, such as approved diets and exercise plans, or smoking status, were subjective and may, therefore, have involved recall bias. Thirdly, the decision to use fasting blood glucose rather than $\mathrm{HbA} 1 \mathrm{c}$ may have resulted in an underestimation of the prevalence of poor glycemic control in the sample, even though fasting blood glucose is reportedly more reliable than $\mathrm{HbAlc}$ according to prior research. ${ }^{50}$ Finally, in this study, patients seen as potential participants were recruited using convenience sampling, which may have involved an element of selection bias.

\section{Conclusion}

This study has found an extremely high prevalence of poor glycemic control in its sample of T2DM patients, in line with the high levels previously reported by research in other Saudi Arabian regional contexts. It found that the most important factors influencing the development of poor glycemic control in this population were a family history of diabetes mellitus, longer diabetes duration, low level of physical exercise, and higher body weight. It is therefore vital that health care professionals focus on the risk factors associated with poor glycemic control in their health strategies, so that they can help to raise levels of glycemic control among diabetes patients across the country to reduce the impact of disease complications and improve the health of its patients. There is a need for prospective longitudinal research using large-scale samples to explore the barriers to controlling T2DM further among patients in Saudi Arabia.

\section{Acknowledgment}

The authors wish to acknowledge the funding they received for this research from the Deanship of Scientific Research at the University of Tabuk, Tabuk, Kingdom of Saudi Arabia (grant number S/1437-0036).

\section{Author contributions}

Riyadh A Alzaheb and Abdullah H Altemani designed this research. Abdullah H Altemani set the study protocol and performed the fieldwork and Riyadh A Alzaheb analyzed the data collected during the study. The two authors collaborated in interpreting the results and establishing the findings, and drafted, checked, finalized, and approved the manuscript together.

\section{Disclosure}

The authors report no conflicts of interest in this work.

\section{References}

1. World Health Organization. Diabetes fact sheet no 312. 2013. Available from: http://www.who.int/mediacentre/factsheets/fs312/en/index.html. Accessed November 21, 2017.

2. Whiting DR, Guariguata L, Weil C, Shaw J. IDF diabetes atlas: global estimates of the prevalence of diabetes for 2011 and 2030. Diabetes Res Clin Pract. 2011;94(3):311-321.

3. Glasgow RE, Ruggiero L, Eakin EG, Dryfoos J, Chobanian L. Quality of life and associated characteristics in a large national sample of adults with diabetes. Diabetes Care. 1997;20(4):562-567.

4. Stumvoll M, Goldstein BJ, von Haeften TW. Type 2 diabetes: principles of pathogenesis and therapy. Lancet. 2005;365(9467):1333-1346.

5. American Diabetes Association. Standards of medical care in diabetes - 2012. Diabetes Care. 2012;35(Suppl 1):S11-S63.

6. Intensive blood-glucose control with sulphonylureas or insulin compared with conventional treatment and risk of complications in patients with type 2 diabetes (UKPDS 33). UK Prospective Diabetes Study Group. Lancet. 1998;352(9131):837-853.

7. Stratton IM, Adler AI, Neil HA, et al. Association of glycaemia with macrovascular and microvascular complications of type 2 diabetes (UKPDS 35): prospective observational study. BMJ. 2000;321(7258):405-412.

8. Saaddine JB, Cadwell B, Gregg EW, et al. Improvements in diabetes processes of care and intermediate outcomes: United States, 1988-2002. Ann Intern Med. 2006;144(7):465-474.

9. Bi Y, Zhu D, Cheng J, et al. The status of glycemic control: a crosssectional study of outpatients with type 2 diabetes mellitus across primary, secondary, and tertiary hospitals in the Jiangsu province of China. Clin Ther. 2010;32(5):973-983.

10. Ong KL, Cheung BM, Wong LY, Wat NM, Tan KC, Lam KS. Prevalence, treatment, and control of diagnosed diabetes in the U.S. National Health and Nutrition Examination Survey 1999-2004. Ann Epidemiol. 2008; 18(3):222-229.

11. Kemp TM, Barr EL, Zimmet PZ, et al. Glucose, lipid, and blood pressure control in Australian adults with type 2 diabetes: the 1999-2000 AusDiab. Diabetes Care. 2005;28(6):1490-1492.

12. Ezenwaka CE, Offiah NV. Differences in cardiovascular disease risk factors in elderly and younger patients with type 2 diabetes in the West Indies. Singapore Med J. 2002;43(10):497-503.

13. Mastura I, Chew BH, Lee PY, et al. Control and treatment profiles of 70,889 adult type 2 diabetes mellitus patients in Malaysia - a cross sectional survey in 2009. Int J Collab Res Intern Med Public Health. 2011;3(1):98-113. 
14. Cheneke W, Suleman S, Yemane T, Abebe G. Assessment of glycemic control using glycated hemoglobin among diabetic patients in Jimma University specialized hospital, Ethiopia. BMC Res Notes. 2016;9:96.

15. Angamo MT, Melese BH, Ayen WY. Determinants of glycemic control among insulin treated diabetic patients in Southwest Ethiopia: hospital based cross sectional study. PloS One. 2013;8(4):e61759.

16. Ghazanfari Z, Niknami S, Ghofranipour F, Larijani B, Agha-Alinejad $\mathrm{H}$, Montazeri A. Determinants of glycemic control in female diabetic patients: a study from Iran. Lipids Health Dis. 2010;9:83.

17. Muoio DM, Newgard CB. Molecular and metabolic mechanisms of insulin resistance and beta-cell failure in type 2 diabetes. Nat Rev Mol Cell Biol. 2008;9(3):193-205.

18. Nichols GA, Hillier TA, Javor KJ, Brown JB. Predictors of glycemic control in insulin-using adults with type 2 diabetes. Diabetes Care. 2000;23(3):273-277.

19. Ahmad NS, Islahudin F, Paraidathathu T. Factors associated with good glycemic control among patients with type 2 diabetes mellitus. J Diabetes Investig. 2013;5(5):563-569.

20. Boutayeb A, Boutayeb W, Lamlili MEN, Boutayeb S. Indirect cost of diabetes in the Arab region. Int J Diabetol Vasc Dis Res. 2013;1(4):24-28.

21. Alharbi NS, Almutari R, Jones S, Al-Daghri N, Khunti K, de Lusignan $\mathrm{S}$. Trends in the prevalence of type 2 diabetes mellitus and obesity in the Arabian Gulf States: systematic review and meta-analysis. Diabetes Res Clin Pract. 2014;106(2):e30-e33.

22. Badedi M, Solan Y, Darraj H, et al. Factors associated with long-term control of type 2 diabetes mellitus. J Diabetes Res. 2016;2016:2109542.

23. World Health Organization (WHO). Body mass index (BMI) classification. Available from: http://apps.who.int/bmi/index.jsp?. Accessed November 24, 2017.

24. Kassahun T, Eshetie T, Gesesew H. Factors associated with glycemic control among adult patients with type 2 diabetes mellitus: a crosssectional survey in Ethiopia. BMC Res Notes. 2016;9:78.

25. Al-Rasheedi AA. The role of educational level in glycemic control among patients with type II diabetes mellitus. Int J Health Sci (Qassim). 2014;8(2):177-187.

26. Khan AR, Al-Abdul Lateef ZN, Al Aithan MA, Bu-Khamseen MA, Al Ibrahim I, Khan SA. Factors contributing to non-compliance among diabetics attending primary health centers in the Al Hasa district of Saudi Arabia. J Family Community Med. 2012;19(1):26-32.

27. Al Balushi KA, Al-Haddabi M, Al-Zakwani I, Al Za'abi M. Glycemic control among patients with type 2 diabetes at a primary health care center in Oman. Prim Care Diabetes. 2014;8(3):239-243.

28. Khattab M, Khader YS, Al-Khawaldeh A, Ajlouni K. Factors associated with poor glycemic control among patients with type 2 diabetes. J Diabetes Complications. 2010;24(2):84-89.

29. Al-Kaabi J, AL-Maskari F, Saadi H, Afandi B, Parkar H, Nagelkerke N. Assessment of dietary practice among diabetic patients in the UAE. Rev Diabet Stud. 2008;5(2):110-115.

30. Al-Ibrahim AA. Factors Associated with Compliance to Diabetes SelfCare Behaviors and Glycemic Control Among Kuwaiti People with Type 2 Diabetes. College Park, MD: University of Maryland; 2012: 314-1328.

31. Mansour AM, Al Shalahi MH, Al Johani A, Rami M. Forward and backward logistic regression analysis to give the estimation of tight diabetes control: review. Int J Diabetes Endocrinol. 2017;2(1):1-4.
32. Adeniyi OV, Yogeswaran P, Longo-Mbenza B, Ter Goon D, Ajayi A1. Cross-sectional study of patients with type 2 diabetes in OR Tambo district, South Africa. BMJ Open. 2016;6(7):e010875.

33. Sazlina S-G, Mastura I, Cheong AT, et al. Predictors of poor glycaemic control in older patients with type 2 diabetes mellitus. Singapore Med J. 2015;56(5):284-290.

34. Mahmood MI, Daud F, Ismail A. Glycaemic control and associated factors among patients with diabetes at public health clinics in Johor, Malaysia. Public Health. 2016;135:56-65.

35. Gong L, Kao WH, Brancati FL, Batts-Turner M, Gary TL. Association between parental history of type 2 diabetes and glycemic control in urban African Americans. Diabetes Care. 2008;31(9):1773-1776.

36. Daly JM, Hartz AJ, Xu Y, et al. An assessment of attitudes, behaviors, and outcomes of patients with type 2 diabetes. J Am Board Fam Med. 2009;22(3):280-290.

37. Sanal TS, Nair NS, Adhikari P. Factors associated with poor glycemic control of type 2 diabetes mellitus: a systematic review and metaanalysis. $J$ Diabetol. 2011;3:1-10.

38. Almutairi MA, Said SM, Zainuddin H. Predictors of poor glycemic control among type two diabetic patients. Am J Med Med Sci. 2013;3(2):17-21.

39. Thent ZC, Das S, Henry LJ. Role of exercise in the management of diabetes mellitus: the global scenario. PloS One. 2013;8(11):e80436.

40. Alneami YM, Coleman CL. Risk factors for and barriers to control type-2 diabetes among Saudi population. Glob J Health Sci. 2016;8(9):10-19.

41. AlQuaiz AM, Tayel SA. Barriers to a healthy lifestyle among patients attending primary care clinics at a university hospital in Riyadh. Ann Saudi Med. 2009;29(1):30-35.

42. American Diabetes Association. Standards of medical care in diabetes. Diabetes Care. 2013;36(Suppl 1):S11-S66.

43. Neiberg RH, Wing RR, Bray GA, et al. Patterns of weight change associated with long-term weight change and cardiovascular disease risk factors in the Look AHEAD Study. Obesity (Silver Spring). 2012;20(10):2048-2056.

44. Shantha GP, Kumar AA, Kahan S, Cheskin LJ. Association between glycosylated hemoglobin and intentional weight loss in overweight and obese patients with type 2 diabetes mellitus: a retrospective cohort study. Diabetes Educ. 2012;38(3):417-426.

45. Adham M, Froelicher E, Batieha A, Ajlouni K. Glycaemic control and its associated factors in type 2 diabetic patients in Amman, Jordan. East Mediterr Health J. 2010;16(7):732-739.

46. Bae JP, Lage MJ, Mo D, Nelson DR, Hoogwerf BJ. Obesity and glycemic control in patients with diabetes mellitus: analysis of physician electronic health records in the US from 2009-2011. J Diabetes Complications. 2016;30(2):212-220.

47. Rock CL, Flatt SW, Pakiz B, et al. Weight loss, glycemic control, and cardiovascular disease risk factors in response to differential diet composition in a weight loss program in type 2 diabetes: a randomized controlled trial. Diabetes Care. 2014;37(6):1573-1580.

48. Scopinaro N, Gianetta E, Civalleri D. Small bowel bypass for obesity. Ann Surg. 1977;186(6):776-777.

49. ALNohair S. Obesity in gulf countries. Int J Health Sci (Qassim). 2014;8(1):79-83.

50. Ghazanfari Z, Haghdoost AA, Alizadeh SM, Atapour J. Zolala F. A comparison of HbA1c and fasting blood sugar tests in general population. Int J Prev Med. 2010;1(3):187-194.

Diabetes, Metabolic Syndrome and Obesity: Targets and Therapy

\section{Publish your work in this journal}

Diabetes, Metabolic Syndrome and Obesity: Targets and Therapy is an international, peer-reviewed open-access journal committed to the rapid publication of the latest laboratory and clinical findings in the fields of diabetes, metabolic syndrome and obesity research. Original research, review, case reports, hypothesis formation, expert opinion and commentaries are all considered for publication. The manuscript management system is completely online and includes a very quick and fair peer-review system, which is all easy to use. Visit http://www.dovepress.com/testimonials.php to read real quotes from published authors. 